\title{
Hands-On Math and Art Exhibition Promoting Science Attitudes and Educational Plans
}

\author{
Helena Thuneberg, ${ }^{1}$ Hannu Salmi, ${ }^{1}$ and Kristof Fenyvesi ${ }^{2}$ \\ ${ }^{1}$ University of Helsinki, P.O. Box 9, 00014 Helsinki, Finland \\ ${ }^{2}$ University of Jyväskylä, Jyväskylä, Finland \\ Correspondence should be addressed to Helena Thuneberg; helena.thuneberg@helsinki.fi
}

Received 24 March 2017; Revised 24 July 2017; Accepted 10 September 2017; Published 18 October 2017

Academic Editor: Seokhee Cho

Copyright (C) 2017 Helena Thuneberg et al. This is an open access article distributed under the Creative Commons Attribution License, which permits unrestricted use, distribution, and reproduction in any medium, provided the original work is properly cited.

\begin{abstract}
The current science, technology, engineering, art, math education (STEAM) approach emphasizes integration of abstract science and mathematical ideas for concrete solutions by art. The main aim was to find out how experience of learning mathematics differed between the contexts of school and an informal Math and Art Exhibition. The study participants $(N=256)$ were 12-13 years old from Finland. Several valid questionnaires and tests were applied (e.g., SRQ-A, RAVEN) in pre- and postdesign showing a good reliability. The results based on General Linear Modeling and Structural Equation Path Modeling underline the motivational effects. The experience of the effectiveness of hands-on learning at school and at the exhibition was not consistent across the subgroups. The lowest achieving group appreciated the exhibition alternative for math learning compared to learning math at school. The boys considered the exhibition to be more useful than the girls as it fostered their science and technology attitudes. However, for the girls, the attractiveness of the exhibition, the experienced situation motivation, was much more strongly connected to the attitudes on science and technology and the worthiness of mathematics. Interestingly, the pupils experienced that even this short informal learning intervention affected their science and technology attitudes and educational plans.
\end{abstract}

\section{Introduction}

Children start to learn mathematics long before they are exposed to formal teaching at school [1]. Nearly all children have some sense of numbers from early on, are capable of counting the basic numbers ("one, two, three, etc."), and are proud to tell their own age. They get to know the basic geometrical shapes and objects like circles, balls, and squares in natural everyday situations. Further, they can tell the time, use money by playing shop, compare and evaluate the magnitude of figures, and strategize, for example, by playing cards. Preschool aged kids get involved with applied mathematics also through ICT and digitalization while playing computer games or using tablet and smartphone applications. This learning of mathematics most often happens unconsciously. This is typically informal learning [2], which can also be utilized in a science exhibition context [3].
However, the older the children, the more complicated the mathematical problems they encounter in everyday situations, especially when they start school. Then, it becomes crucial to exploit their natural curiosity, imagination, and willingness to play [4] in the learning of mathematics and to support them to discover the meaningfulness and worth of mathematics. According to the TIMSS 2015 study (TIMMS: Trends in International Mathematics and Science Study), half of the international fourth-grade mathematics curricula include attitudes and mention, for example, beliefs, confidence, and perseverance as well as the beauty of mathematics, developing a productive disposition toward mathematics, appreciating the practical applications of mathematics in life, and displaying a constructively critical attitude toward mathematics [5]. Some countries mention appreciation of scientific inquiry and science as a discipline or curiosity and interest. 
The current science, technology, engineering, art, mathematics education (STEAM) approach underlines integration of abstract mathematical ideas to find concrete solutions and evidence by art [6]. Children have to be able to use their senses and hands-on experimentation in order to test their thinking, especially at the concrete operational stage [7]. The importance of own exploration and experience is supported by the principle of learning by doing by Dewey [8] and the key of science center pedagogy, hands-on activity by Oppenheimer [9]. In case of math learning, manipulation of materials in multiple ways allows abstract mathematical concepts to become understandable, creative problem-solving to become possible, and mathematics to become meaningful [10]. Hands-on activities and exploration involve factors that enhance creativity: the encouragement of questions and novel initiatives and the offering of opportunities to discuss and debate problems with others [11]. Usually, these are perceived as welcoming challenges by high-achieving students. The empirical results of a study by Mann [12] that explored elements of mathematical creativity in middle school students showed that the strongest predictor was math achievement; it explained one-quarter of the variance. And one half of that predicted gender, attitudes toward mathematics, and belief in one's own creative abilities. However, mathematical giftedness does not always guarantee mathematical creativity [13]. Further, high achievement or giftedness can sometimes be connected with perfectionism, in which case a fear of failure might turn to avoidance orientation and lead to underachievement as Mofield et al. [14] stated.

Pupils have shown that, through using a hands-on method, they like learning more, learn and remember better [15], and attribute their learning outcomes more to hands-on than to traditional teaching methods, or only to seeing or to hearing things. Liking and motivation have been shown to be connected to developing mathematical metacognition, which along with reduced anxiety supports problem-solving [16]. As with the children, teachers have reported that the handson method has been the most effective method for their pupils [17]. These benefits of the hands-on method have been shown to apply to a diverse number of learners, from pupils with mild disabilities [18] to pupils with serious emotional disturbances [19].

In this article, mathematical problem-solving was combined with art. The learning context was a Math and Art Exhibition, and the mix of math learning and art was represented in the building of mathematical geometric models with concrete materials. These activities require visual imagery and mental rotation. According to Hope [20], the capacity and skill to create visual representations of the mental images form an essential part of the learning process. Although the immediate goal was to enhance math learning, these activities support the development of spatial skills [21] and spatial intelligence, which have been identified as important factors of school achievement in general [22].

According to Fenyvesi et al. [23], problem-solving can also be a basis for the integration of learning mathematics in transdisciplinary educational frameworks, such as STEAM integration, although the integration of liberal arts into STEM is mutually reshaping scientific education and humanities education [24]. It seems evident that, just like mathematics learning, it is recommended that science, technology, engineering, and arts education also follow problem-oriented approaches.

As the creative element and esthetic component are the inherent core of art, combining art with math learning offers an additional dimension for concretizing math concepts. Art and math have been considered to share many principles, for example, space and shape [25], but also that of esthetics, as Mack [26] discusses in his article "A Deweyan perspective on esthetic in mathematics education." The synthesis of math and art might show the beauty of both domains and possibly in a novel light. As such, by applying art, ways of looking and observing become critical [27].

Making art, "Kunst," requires practical skills and handicraft. However, it is also an emotional process involving play, risk-taking, and imagination. The imagination has often been undermined in teaching academic school subjects, although it is crucial for "inventive scholarship" [28]. A combination of math and art invites pupils to approach math problems from a new perspective [29] because imagination, which is closely related to art, gives the possibility of "seeing things other than the way they are", as Eisner [28] states. When this artistic math learning process with its esthetic beauty is shared with others, it creates an emotional experience, which then is likely to support also cognitive learning and the retention of learned contents and skills [30] and the "convergence of both cognitive and emotional parts of the mind" [26]. Because mathematical problem-solving has been shown to involve affective factors [16], such as anxiety, these kinds of shared activities might ease negative experiences and feelings.

Although art in science has recently become more prominent in the move from STEM to STEAM [23], according to Hickman and Huckstep [29], the role of art, at least in math education, lacks research evidence. However, there are more recent results related to this topic [31-33].

Learning in informal contexts has often been regarded as the opposite of formal education and critical toward traditions as is depicted in Ivan Illich's [34] classical presentation Deschooling Society. One of the main difficulties is that pure informal learning refuses to be categorized, and the definitions are not needed until informal learning becomes institutionalized. In this sense, it has often been described as a creative way of learning as is the case in Gardner's [35] book, The Unschooled Mind, which he points out also with the element of reframing [36].

The main results related to informal creative exhibition learning underline the motivational effects. In particular, the role of situation motivation seems to be essential [37]. Also, novelty has turned out to be one of the key factors in creating interest and situation motivation in the open learning environment [33], which can be interest-based settings that motivate otherwise non-mathematically oriented pupils. The dilemma of the informal creative pedagogy is how to enhance this strong situation motivation to support its transformation into intrinsic motivation and deep-learning strategy. As such, it is also a challenge of this study and is embedded in the main research questions. 
Research Questions. The research questions were as follows:

(1) How does the pupils' experience of learning mathematics differ in the school context and in the exhibition context?

(2) How does the experienced worth of mathematics and belief of hands-on effectiveness on learning change after the Math and Art Exhibition?

(3) What is the role of situation motivation and other variables on change of attitudes toward science and technology and on the future educational aspirations of pupils?

These questions are analyzed in regard to gender and math achievement groups. The role of cognitive, visual reasoning, autonomous motivation, and pretest variables was controlled in the constructed SEM model.

\section{Materials and Methods}

2.1. Participants. The participants in Math and Art Exhibition were 12 to 13 years old from a city in Middle Finland $(N=$ $256), 52 \%$ girls $(n=134)$ and $48 \%$ boys $(n=122)$. The five randomly selected schools were chosen from the schools which had preregistered for the mobile exhibition. The study was conducted following the research's ethical principles.

\subsection{Context of the Study: Learning Mathematics by Hands-On} Activities. The context of this study was a mobile interactive mathematics exhibition Art of Math. The exhibition consisted of eleven interactive "hands-on" science exhibition objects, which the students were allowed to use, test, explore, and learn freely during a 45 -minute time period. Following that, they attended a workshop (also 45 minutes) in which they were allowed to build their own structures and creatures by using and applying the small "Lego" type of plastic pipes and circles.

The 4Dframe construction system and building set was developed by Park Hogul, who is a Korean engineer and model maker originally inspired by classical Korean architecture [23] with inspirations of other mathematical and artistic approaches [33]. His concept is based upon the structural analysis and geometric formalization of building techniques utilized in the construction of Korea's traditional, wooden buildings. The set itself consists of $2-30 \mathrm{~cm}$ long "tubes" and various types of "connectors": just a small number of elegantly structured, simple module pieces made out of polypropylene, which are flexible enough for the construction of "unbreakable" modules and spatial formations as well [23]. The wealth of structural variability offered by this versatile device renders it an excellent tool for conceptualizing, modeling, or analyzing structures and topics relevant to geometry, engineering, architecture, design, or art. Due to its numerous advantages and flexibility, the 4 Dframe is adaptable to a wide variety of complex educational uses [23].

The central aim underlying 4Dframe educational methodology [38] is to activate students' familiarity with geometric structures within the context of problem-solving. This method is based upon the creative exploration of these structures and uses a step-by-step approach to scientifically analyze each stage in the construction process. The 4 Dframe also provides opportunities to experiment with creative methods related to mathematical art.

\subsection{Measures}

2.3.1. Deci-Ryan Autonomous Motivation. The Deci-Ryan scale measuring autonomous motivation was based on selfdetermination theory (SDT). It was administrated as a pretest, and the variable was used as a covariate in the structural equation model in order to reveal the purified influence of the short-time situation motivation in the exhibition context.

The Deci-Ryan Motivation (SRQ-A: Self-Regulation Quality-Academic) scale has 32 standardized items with four Likert options: $1=$ not at all true, $2=$ not nearly true, 3 = somewhat true, and $4=$ totally true (for the translation into Finnish, see Thuneberg, 2007). The questions correspond with the self-regulation styles on the self-determination continuum. For example, the students are asked about the reasons why they do their homework or try to answer hard questions during lessons. The summative variables forming the self-determination continuum from the external toward the intrinsic direction are as follows: external, introjected, identified, and intrinsic. Based on the formula by Ryan and Connell presented in the validation article of the SRQ-A [39], the RAI (Relative Autonomy Index) of the summative variables (i.e., external, introjected, identified, intrinsic) was calculated. The RAI describes the overall relative autonomy level of the pupil. The positive plus sign in RAI indicates that the experience is rather autonomous, and the negative minus sign indicates that one relies more on others than trusting in one-self.

The reliability of the SRQ-A was checked. It was good, Cronbach's $\alpha=.895,32$ items.

2.3.2. Situation Motivation Test. The situation motivation questionnaire consisted of 12 Likert scale items (scale: 1-5, from "totally agree" to "totally disagree"). The questionnaire was constructed by the authors, piloted in a small group of 12-year-olds, and used before this present study in other studies. The questionnaire was administered as a posttest. The items were constructed and instrumentalized in relation to extrinsic elements like "edutainment" and recommendable outer aspects. The questions explored how attractive the pupils viewed the exhibition, for example, as follows: I was able to experiment and do many things by myself; I wish I would have had a chance to stay longer at the exhibition; I would recommend the math exhibition to others. The reliability of the measure was good, Cronbach's $\alpha=.895,12$ items.

2.3.3. RAVEN Test. The cognitive measure was the visual reasoning test RAVEN Standard Progressive Matrices [40]. The test measures visual nonverbal cognitive skills [41]. It has been shown to be a reliable standardized tool for comparing an individual's learning abilities with the age group, irrespective of sex.

In each test item, the subject is asked to identify the missing element that completes a pattern. The test contains 60 items divided into five sets (A, B, C, D, and E), each including 
12 different tasks. The reliability was good, Cronbach's $\alpha=$ $.845,60$ items.

2.3.4. Math Achievement. Math grade was used as a math achievement indicator. The scale of the school subject grades in Finland goes from 4 to 10. In addition to using the math grade as a continuous variable, pupils were categorized in math achievement quartiles, and that grouping was applied in the analyses.

Liking Math at School Context and Liking Math at Exhibition Context. The single variables, which were summed, were formulated by the authors and were the same in the preand posttest. The only exception was that in the first one the items were related to school and in the second to exhibition. Following are examples of the 14 semantic differential items: I think that math learning at the school/at the exhibition was important/useless (scale 1-5, with 5 indicating "important" and 1 indicating "useless"), modern/old-fashioned (scale 1-5, with 5 indicating "modern" and 1 indicating "old-fashioned"), and clear/confusing (scale 1-5, with 5 indicating "clear" and 1 indicating "confusing"): pretest Cronbach's $\alpha=.90,14$ items; posttest Cronbach's $\alpha=.90,14$ items (note: in pretest, time point 1 has been abbreviated to T1; in posttest, time point 2 has been abbreviated to T2).

2.3.5. Experienced Worth of Maths. The summed variable was formed out of six single variables formulated by the authors. The question was, What do you think of the statement? The scale ranged from 1 (not agree at all) to 5 (totally agree). The statements were as follows: Math makes my everyday life easier. Understanding mathematics supports me in many practical situations. It is important to understand mathematical phenomena. Mathematics is interesting. Mathematics is useful in many occupations: pretest Cronbach's $\alpha=.86,5$ items; posttest Cronbach's $\alpha=.82,5$ items.

The next three measures were single items. It is rather unconventional to apply single-item variables, but single items have been shown to yield reliable and valid data and predict outcomes effectively in certain conditions [42-45]. They even might be more economical and suitable than multiple item measures [46-48]. The three items of our study met the prerequisites of usage of single items based on the literature $[49,50]:(1)$ they are concrete and simple, not multifaceted; (2) they relate soundly to the other instruments; (3) they are integral parts of (the second and third) research questions; and (4) they fit in our sample consisting of young children who are most likely impatient and not willing to answer many extra questions that only slightly differ from each other.

2.3.6. Experienced Effectiveness of Hands-On on Learning. This variable in pre- and posttest was based on a single question. The question was, What do you think of the statement? The statement was, By hands-on experimentation and testing I can learn effectively. The scale ranged from 1 (not agree at all) to 5 (totally agree).
2.3.7. Exhibition Enhances My Science and Technology Attitudes. This variable was based on a single question. The question was, What do you think of the statement? The statement was, Due to the math exhibition my attitudes toward science and technology changed in a more positive direction. The scale ranged from 1 (not agree at all) to 5 (totally agree).

2.3.8. Exhibition Affected My Future Educational Plans. This variable was based on a single question asking about educational plans in general. The question was, What do you think of the statement? The statement was, I believe that the math exhibition influences my future educational plans. The scale ranged from 1 (not agree at all) to 5 (totally agree).

2.4. Data Analysis Methods. The mean differences and the change between the pre- and posttest were analyzed by General Linear Modeling (GLM; univariate, multivariate, and repeated measures) method. The effect-size measure was partial $\eta^{2}$ coefficient $\left(\eta^{2}>.01\right.$ small, $>.06$ middle, and $>.14$ large), which is as acceptable as the recommended generalized coefficient when only one grouping factor is used [41]. Graphical plots were used, as recommended, to illustrate the pre- and posttest levels and the change between the preand posttest [51].

To answer the third research question and to see how our data would fit in the theoretical model, we applied SEM, the structural equation modeling (AMOS 22). The RAI, gender, RAVEN, math grade, belief of hands-on effectiveness on learning T1, and math worth $T 1$ were used as covariates to control their effects on measured posttest variables. The goodness of fit of the models was based on a $\chi^{2}$ test $(p>.05)$ and indices of NFI, TLI, and CFI (good fit $>.90$, or better $>.95)$, RMSEA reasonable fit $<.08$, good fit $<$ .05 [52]. The predictors were indicated by standardized $\beta$ coefficients, and $R^{2}$-multiple correlation indicated the total variance explained.

For testing the invariance of the models across genders and across math achievement quartiles, the unconstrained and fully constrained overall models were compared and the invariance was evaluated based on the $\chi^{2}$ test.

2.5. Missing Values. There were on average $6 \%$ missing values. The maximum likelihood method and estimation of means and intercepts were used in the SEM path analysis due to the missing values.

\section{Results}

In Tables 1 and 2, we present the statistical descriptors of the variables and the significant differences between the boys and girls and between the math achievement percentiles. In addition, the overall and between-group change are explained in regard to the pretest situation and posttest situation.

3.1. Math Achievement. The overall mean of math was 8.19 $(\mathrm{SD}=1.138)$. The difference between girls $(\mathrm{M}=8.28, \mathrm{SD}=$ $1.083)$ and boys $(\mathrm{M}=8.09, \mathrm{SD}=1.194)$ was nonsignificant 
TABLE 1: Statistical descriptors by gender.

\begin{tabular}{|c|c|c|c|c|c|c|}
\hline & $N$ girls & Mean & Std. dev. & $N$ boys & Mean & Std. dev. \\
\hline RAVEN & 134 & 37.060 & 6.600 & 122 & 36.246 & 8.454 \\
\hline RAI & 132 & .107 & 1.963 & 120 & -.196 & 1.557 \\
\hline Math grade & 131 & 8.282 & 1.083 & 116 & 8.095 & 1.194 \\
\hline Math at school & 133 & 3.359 & .599 & 121 & 3.324 & .804 \\
\hline Math at exhibition & 119 & 3.327 & .601 & 107 & 3.268 & .734 \\
\hline Situation motivation & 120 & 3.143 & .717 & 106 & 3.118 & .817 \\
\hline Math worth Time 1 & 132 & 3.617 & .888 & 122 & 3.537 & .960 \\
\hline Math worth Time 2 & 133 & 3.584 & .818 & 122 & 3.523 & .878 \\
\hline Hands-on I learn effectively Time 1 & 132 & 4.061 & .914 & 121 & 3.860 & 1.128 \\
\hline Hands-on I learn effectively Time 2 & 133 & 3.805 & .981 & 119 & 3.849 & 1.110 \\
\hline Exhibition enhanced science \& technol. attitudes & 119 & 2.647 & 1.038 & 105 & 2.895 & 1.126 \\
\hline Exhibition influenced future educational plans & 121 & 2.174 & 1.070 & 106 & 2.302 & 1.088 \\
\hline
\end{tabular}

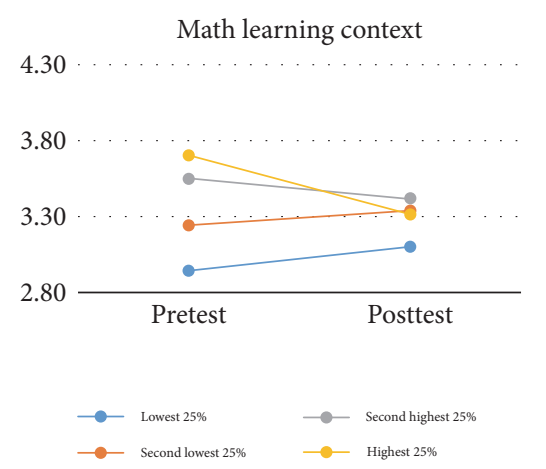

(a)

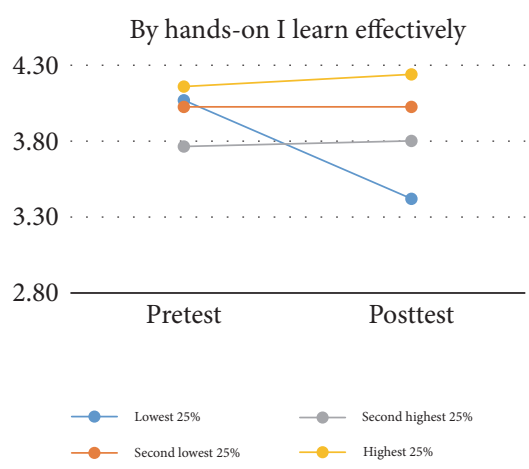

(b)

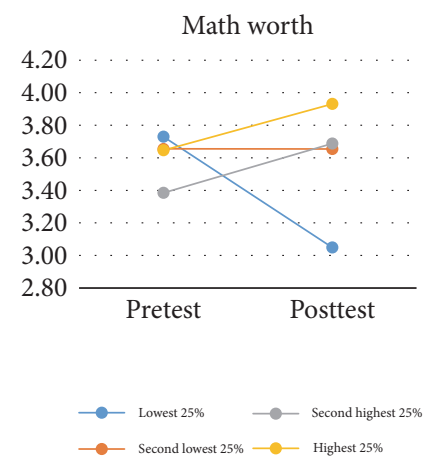

(c)

FIGURE 1: Liking of math learning in the school context and in the exhibition context (a); by hands-on I learn effectively T1 and T2 (b); and math worth $\mathrm{T} 1$ and $\mathrm{T} 2$ (c) by math achievement quartiles.

( $p=.197$ ) (note: mean is abbreviated as $\mathrm{M}$ and standard deviation is abbreviated as SD)

3.2. Learning Math in School Context and in Exhibition Context. The mean of liking math learning in the school context and liking it in the exhibition context was rather good on the absolute Likert scale (see Table 1). The differences between the genders were nonsignificant in both contexts (school context, $p=.213$; exhibition context, $p=.807)$. The difference between the math achievement quartiles, however, was significant in school context $(F(\mathrm{df}=3)=11.933, p=$ .000 , partial $\eta^{2}=.144$; large effect size, lowest quartile versus third and highest quartiles, $p=.000$; second quartile versus third quartile, $p=.023$; and fourth quartile, $p=.015)$, but nonsignificant in exhibition context, $p=.086$.

Clearly, the math achievement quartiles differed in the change (measured by GLM repeated measures method) from the math learning school context to the math learning exhibition context (Wilks' lambda $=.949, F=3.851, \mathrm{df}=3, p=.010$, partial $\left.\eta^{2}=.051\right)$. The change of the highest math achievement quartile was different from the lowest $(p=.001)$, the second highest from the lowest $(p=.000)$, and the second lowest from the lowest $(p=.033)$. The drop in the two highest percentiles was significant.

We illustrate the results by graphs. Liking math learning in the school context and liking math learning in the exhibition context by math achievement quartiles are presented in Figure 1(a).

3.3. By Hands-On I Learn Effectively. The means of by handson I learn effectively $\mathrm{T} 1$ and $\mathrm{T} 2$ were good in the scale 1-5 (see Table 1). The overall change between by hands-on I learn effectively $\mathrm{T} 1$ and $\mathrm{T} 2$ was shown to be nonsignificant. However, the change was significant in the girls' group (Wilks' lambda $=.970, F=4.083, \mathrm{df}=1, p=.045$, partial $\eta^{2}=.030$; $\mathrm{M} 1=4.061, \mathrm{SD} 1=.918 ; \mathrm{M} 2=3.809, \mathrm{SD} 2=.970)$ but not in the boys' group, $p=.859(\mathrm{M} 1=3.864, \mathrm{SD} 1=1.124$, M2 = 3.839, SD2 = 1.109); see Figure 2 .

The time and interaction effect with the math achievement quartiles was significant (Wilks' lambda $=.963, F=$ 3.019 , df $=3, p=.031$, partial $\left.\eta^{2}=.037\right)$. The change was significantly different between the lowest and highest quartiles $(p=.041)$. Before the math exhibition, the lowest achievement quartile pupils did not differ in by hands-on I 


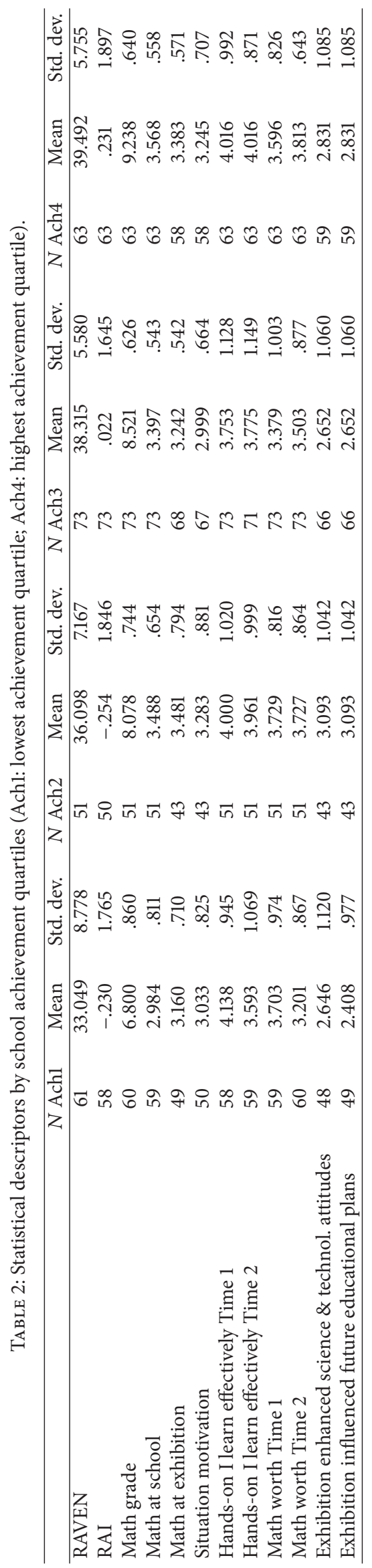




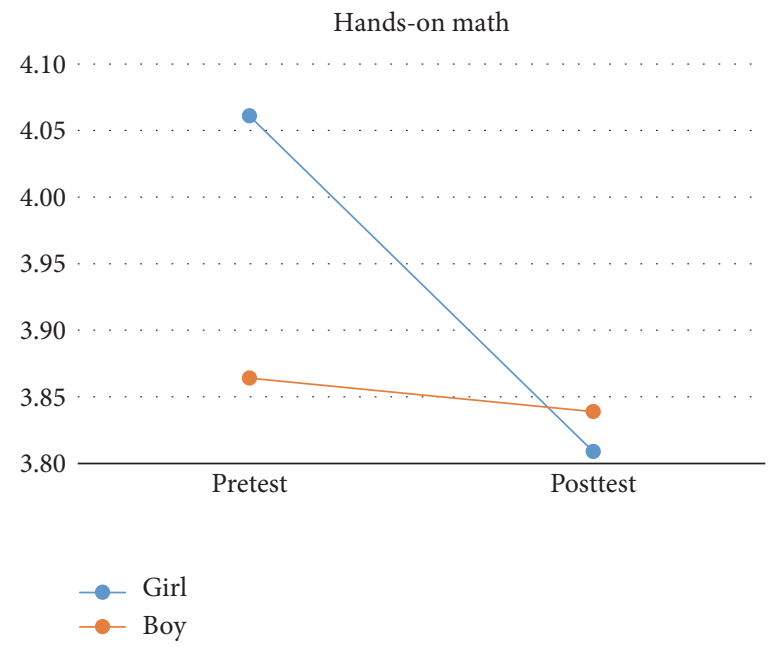

FIGURE 2: By hands-on I learn effectively, pre- and posttest plots by gender.

learn effectively from the other groups $(p=.121)$, but the mean decreased significantly in the lowest group after the exhibition (see Figure 1(b)).

3.4. Math Worth. The statistical descriptors are presented here. The mean of math worth at both time points was rather good on the absolute Likert scale (see Table 1).

Changes from Pretest to Posttest. The overall change in experienced math worth was shown to be nonsignificant, and there was no difference in that regard between the genders. However, in regard to between the math achievement quartiles, the change was significant with a middle size effect (Wilks' lambda $=.903, F=8.574$, df $=3, p=.000$, partial $\left.\eta^{2}=.097\right)$. The change was significantly different between the lowest and highest quartiles $(p=.043)$. Before the math exhibition, the lowest achievement quartile valued math significantly more than after the math exhibition, having a large effect size (Wilks' lambda $=.741, F=19.941$, df $=1, p=$ .000 , partial $\left.\eta^{2}=.259\right)$. The mean increased in the highest and second highest quartile but was significant only in the last mentioned (Wilks' lambda $=.944, F=4.689, \mathrm{df}=1$, $p=.033$, partial $\left.\eta^{2}=.05\right)$; see Figure $1(\mathrm{a})$.

3.5. SEM Path Analysis. The relative autonomy index (RAI), gender, cognitive visual reasoning (RAVEN), math achievement, math worth $\mathrm{T} 1$, and by hands-on I learn effectively $\mathrm{T} 1$ were used as covariates to control their effects on the measured variables (situation motivation; exhibition enhanced my science and technology attitudes; and exhibition affects my future educational plans). The final model containing only significant effects was shown to fit the data well: $\chi^{2}=32.928$, $\mathrm{df}=39, p=.742, \mathrm{NFI}=.941, \mathrm{TLI}=1.021$, CFI $=1.000$, and RMSEA $=.000$.

The final path model is presented in Figure 3. The magnitude of the paths (the standardized beta-coefficients) is shown with the indicators of significance $\left({ }^{*} p<.05,{ }^{* *} p<\right.$ .01 , and $\left.{ }^{* * *} p<.001\right)$ and the total explanation by $R^{2}$.

In the following, first, the effects of the covariates are explained.

(1) After being controlled by other variables, of which only math grade was significantly correlated, visual reasoning predicted "exhibition enhanced my attitudes to science \& technology."

(2) Math achievement directly predicted by hands-on I learn effectively T2, math worth T2, and to a smaller degree exhibition influences my educational plans. In addition, math achievement indirectly predicted math worth T2 and situation motivation. The invariance test was applied using math achievement quartile groups as the moderator. The test showed that the models were invariant (chi-square difference $=41.916, \mathrm{df}=33, p=.137)$.

(3) Autonomous motivation directly predicted situation motivation. Indirectly by hands-on I learn effectively $\mathrm{T} 2$ predicted math worth T2, "Exhibition enhanced my attitudes towards science and technology," and "Exhibition influences my educational plans."

(4) By hands-on I learn effectively T1 correlated with math worth T1. It did not predict any of the measured variables, not even math worth T2.

(5) Math worth T1 predicted Exhibition enhanced my attitudes toward science \& technology and Exhibition influences my educational plans, the last mentioned also indirectly.

(6) Gender predicted only one variable: Exhibition enhanced my attitudes toward science \& technology.

Further invariance tests gender as the moderator allowed to examine that in more detail. The test showed that the models were noninvariant (chi-square difference $=21.202, \mathrm{df}=13$, $p=.069)$; thus, the same model did not fit for both boys and girls. Hence, the analysis continued path by path. The analysis revealed that the two paths differed, and in both cases the connection was stronger among girls than among boys: (1) path from situation motivation to Exhibition enhanced my attitudes toward science \& technology T2 $(z=2.396, p<.05$; 


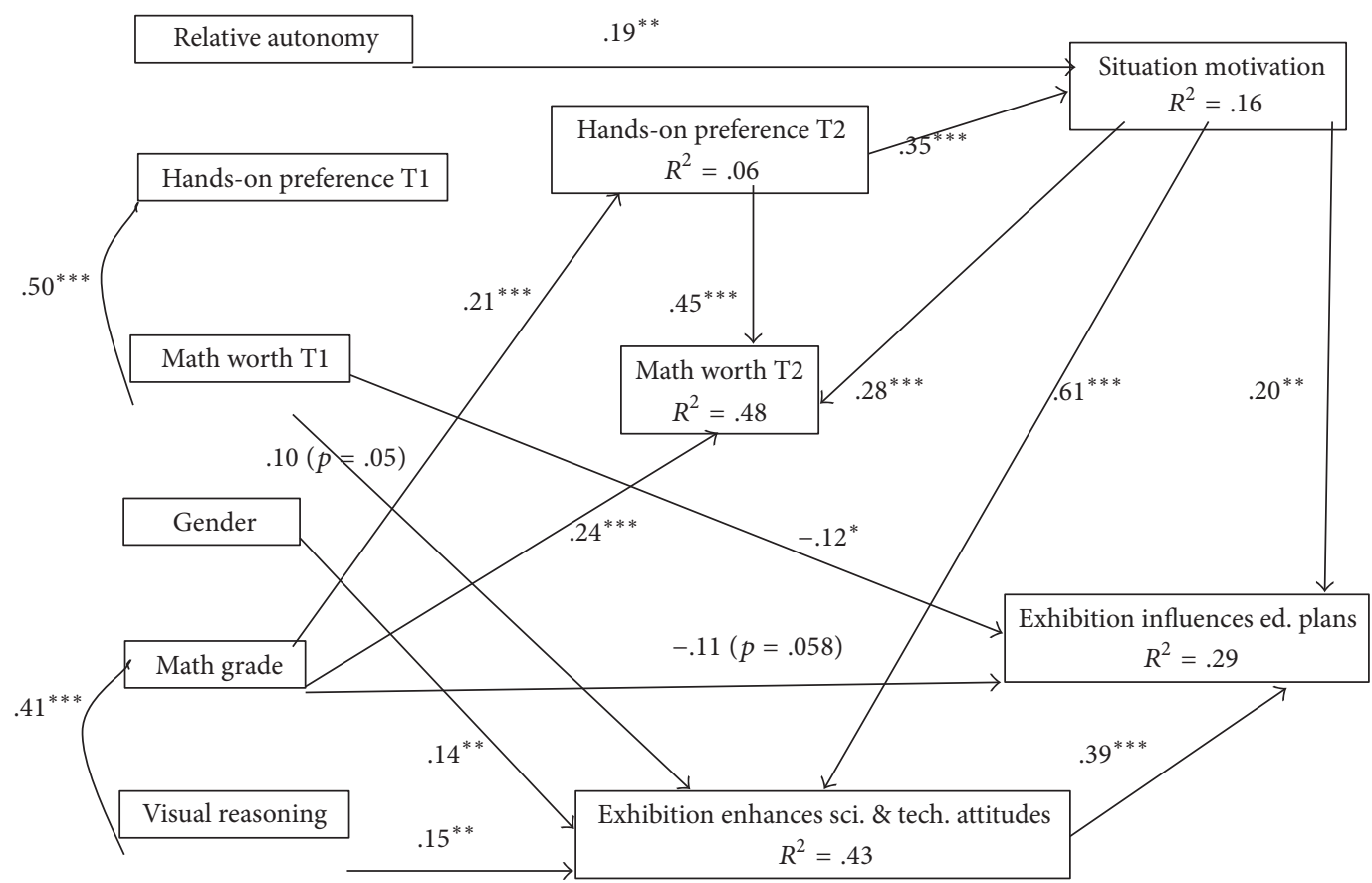

Figure 3: The final path model $\left({ }^{*} p<.05 ;{ }^{* *} p<.01 ;{ }^{* * *} p<.001\right)$.

girls, std. $\beta=.73$; boys, std. $\beta=.51$ ) and (2) connection from situation motivation to math worth T2 to Exhibition enhanced my attitudes toward science \& technology $T 2(z=2.431$, $p<.05$; girls, std. $\beta=.40$; boys, std. $\beta=.17$ ).

In the following, the effects of and on the posttest variables are explained.

(1) By hands-on I learn effectively $T 2$ had an effect on math worth T2 and situation motivation and indirectly also on Exhibition enhanced my attitudes toward science \& technology and Exhibition influences my educational plans. By hands-on I learn effectively $\mathrm{T} 2$ was explained by $6 \%$ by math grade.

(2) Situation motivation had an effect on Exhibition enhanced my attitudes toward science \& technology, math worth T2, and Exhibition influences my educational plans, with the last mentioned being affected also indirectly. The other variables, autonomous motivation and by hands-on I learn effectively T2 directly explained $16 \%$ of situation motivation.

(3) The variables of the model explained $48 \%$ of experienced math worth T2, but its effects on other variables (i.e., Exhibition enhanced my attitudes toward science \& technology (std. $\beta=.04$ ) and Exhibition influences my educational plans) did not reach significance.

(4) Exhibition enhanced my attitudes toward science \& technology had an effect on Exhibition influences my educational plans. The variables, which contributed to the explanation of its variance, visual reasoning, gender, math worth T1, and situation motivation, explained $43 \%$ of it.

(5) Exhibition influences my educational plans was explained with $29 \%$ by other variables, math grade, math worth T1, and situation motivation and, in addition, indirectly by autonomous motivation and by hands-on I learn effectively.

\section{Discussion}

4.1. Yes, They All Liked Math, but Interestingly the Lowest Math Achievers Prefer Learning at the Exhibition. First, we have to add that in this kind of research design we cannot claim that the changes in any of the variables are due to one short science exhibition visit; there are lots of possible uncontrollable factors involved. However, we report both what was before the exhibition and how the variable values changed following the exhibition. We consider that the exhibition is one option as it was a planned educational experience that was comprised of elements that have shown to be related to effective learning. The first research question asked how the pupils experienced learning of mathematics in the school context compared to the exhibition context. It was a positive result that both means of liking math learning at school and liking math learning at exhibition context were rather good on the absolute Likert scale at school, meaning that in general pupils liked learning math independent of the context. Like/dislike results can be reflected against international results, which have shown that overall 15 to $22 \%$ of pupils dislike mathematics [5].

Based on the data, the math grades of boys and girls were equal. The math achievement result parallels the results of the TIMSS 2015 study in which gender equity of fourth-graders' math results was found in half of the 49 participating countries. However, Finland actually belonged to the minority in TIMMS, with girls outperforming boys. It was interesting to note that both girls and boys also equally appreciated math learning at school and at the exhibition.

However, the experiences were different when it came to math achievement grouping. It was clear that the lowest achieving group appreciated the exhibition alternative for 
math learning compared to learning math at school. This makes sense from the cognitive perspective as, according to Oppenheimer [9], manipulation of materials supports understanding abstract mathematical concepts and makes math more meaningful, which is especially shown to benefit diverse learners $[15,18]$. From an emotional perspective, the different kind of learning context might promote a decrease of anxiety, which has been shown often to be related to math learning and to the manipulating of numbers and problem-solving, which may be especially so for students with mathematical learning difficulties [16]. But even at school they did not dislike it, as their average 3.01 was just in the middle of the 1-5 scale. At school, they liked math learning least of all the groups but closed the gap later; at the exhibition, they liked math learning as much as the others. However, the gap closing between the math percentiles was partly due to the highest achieving group's drop in liking math learning at the exhibition compared to learning at school and to a smaller degree due to the second highest group's smaller drop. So they, in turn, did not appreciate the exhibition alternative as much as the learning at school. One reason, at least for some of them, might be in the novelty of the situation, which provides a risk: one cannot safely repeat learned strategies and must thus face also a possibility of failure. According to Mofield et al. [14], this kind of situation can prevent those high-achieving students with a high degree of perfectionism from reaching their full potential. Although Mann [12] observed that math achievement has been shown to be an important predictor of mathematical creativity, the majority of the variance remained unexplained in his model, which also applies to other results, which indicates that math achievement is not always connected to math creativity [13].

\subsection{Beliefs before and after the Exhibition: Distinct Entities,} Different Worlds. The second research question was related to the change of experienced worth of mathematics and the change of belief of hands-on effectiveness on one's learning after the exhibition. Combining math learning with experimentation and art in a concrete model building process in the exhibition was a many-sided and versatile approach. In this study, pupils in average believed before and after the exhibition that they learn effectively by hands-on method. It was baffling and unexpected after just a short exhibition visit that based on the SEM-model the belief was not stable from the pretest to the posttest belief after the exhibition, in SEMtechnical language: the pretest did not predict the posttest. Similarly experienced worth of mathematics was not stable but differed in the posttest situation. These results point in the same direction as Burn's and Silbey's findings [53]: there is a risk that pupils do not see the connection between the different learning contexts of the traditional classroom and the out-of-school exhibition. In the context of the Math and Art Exhibition, this phenomenon turned out to be a conflict between hands-on learning and the traditional pencil-andpaper method at school.

The experience of hands-on effectiveness on learning at the school and at the exhibition was not consistent across the subgroups. Boys felt to an equal degree that the method was effective in both contexts. However, in turn, that belief plummeted among the girls. Previous studies have found that boys tend to prefer hands-on approach over other kinds of methods, at least in science learning [37, 54]. The experienced worth of doing math did not differ between genders.

There was also a drastic drop in the belief of the lowest math achievement quartile of the hands-on methods' effectiveness on their learning, and there was a similar one in their belief in the worth of math. So, they appreciated the opportunity to do something differently as was shown by the comparison of the math learning context at school/at the exhibition, but at the same time they somewhat lost belief in their ability to take advantage of its possibilities, meaning the hands-on and art combination and problem-solving by building the models. They also began to hesitate about the worth of mathematics, which included whether or not mathematics could make their everyday life easier, its usefulness in working life, the importance of understanding mathematical phenomena, and whether mathematics is interesting at all. The higher achievers kept their belief in the hands-on effectiveness of learning despite the result that the higher achieving groups did not like the change of learning context from the school to the exhibition. The worth of math, in turn, increased in the two highest math achieving percentile groups.

4.3. Situation Motivation: A Powerful Attitude Booster Especially among Girls. The third research question related to situation motivation's and other variables' role in change of attitudes toward science and technology and future educational plans. We found that situation motivation was the most powerful explainer especially in regard to the experienced exhibition influences on science and technology attitudes, and it also affected future educational plans. These results imply increased metacognition, the awareness of what one thinks and plans, like Lai et al. [16, p. 2] observed: "Motivation is an important energizing factor of metacognition and can activate the self-regulation process."

Situation motivation was boosted by relative autonomy experience. The previous results relating to differences between genders in autonomous motivation are mixed; some have found differences [54]; some have not [37, 54]. In the present study, the difference in autonomous motivation experience was nonsignificant between the boys and girls. Hence, in both groups, it equally predicted situation motivation. Overall, the pupils experienced themselves as nonautonomous because the RAI remained negative. In order to enhance situation motivation and, indirectly, the future plans, more degrees of freedom most likely would have been beneficial. The results in science learning context by Jalil et al. (2009) support this [55]. Also, experienced hands-on effectiveness of learning enhanced situation motivation-pupils who preferred that method found the exhibition, with its experimenting and model building, more attractive.

The experienced positive science and technology attitude change influenced future educational plans of the students most strongly. The boys experienced more than the girls that the exhibition was useful and fostered their science and technology attitudes. On the other hand, boys and girls did not 
differ in situation motivation, but based on the path-by-path comparison due to the significant result of using gender as the moderator, the experienced attractiveness of the exhibition among girls was much more strongly connected to the science and technology attitudes than among the boys. Similarly, situation motivation enhanced the experienced worth of mathematics among girls more than among boys. These are important results, revealing more specifically attributes of motivation, science and technology attitudes, and their connection to future educational aspirations. For their part, the results answer Osborne et al.s [2003, p. 1] call for research [56]: "The literature itself points to the crucial importance of gender and the quality of teaching. Given the importance of the latter we argue that there is a greater need for research to identify those aspects of science teaching that make school science engaging for pupils." The answer is to bring motivational, concrete, and creative elements from the informal STEAM exhibitions to school and, thus, narrow the gap between traditional and experimental teaching. The researchers agree with the need for enhancing creativity in math education at school [cf. [12, 13, 57]].

The math grade and the question of the worth of mathematics asked before the exhibition predicted how pupils experienced the effect of the exhibition on their educational plans. These direct effects were negative, which implies that those who were not high achieving and who did not believe in the worth of mathematics before perceived more positively the effect of the exhibition on their attitudes toward science and technology and their educational plans than the others. However, it is worth noting that the others might already have had positive attitudes and simply did not believe that the exhibition had changed them.

Math achievement and the worth of mathematics before the exhibition had as well, however, a positive, indirect role on the plans either via situation motivation or via change of science and technology attitudes. This means that the higher the math achievement or experienced mathematics worth is, the more positive the attitudes were and the more the exhibition was believed to enhance the educational plans. Similarly, the experienced effectiveness of hands-on method on learning in the exhibition and autonomous motivation affected the attitudes and plans positively.

As already mentioned in relation to the answer to the second research question, the experienced worth of mathematics before and that after the exhibition were found to be quite separate entities. The latter did not seem to have any relevance in the minds of pupils in this context, as it did not predict the science and technology attitudes or the educational plans.

Based on the RAVEN test theory, boys and girls did not differ in the cognitive, visual reasoning test. Visual reasoning predicted the experienced exhibition influences on the science and technology attitudes but indirectly also on future educational plans.

\section{Conclusions}

In this article, art was combined with math. The learning context was the Math and Art Exhibition. The main results of this study support the earlier key findings of motivation and learning reported in the literature $[58,59]$. In the exhibition, hands-on math learning was mixed with art by workshop, which allowed the pupils to build mathematical structures. This creative component was to provide an esthetic experience via shaping the beauty and sense of wholeness and aimed to lead to more effective math learning. Thus, building the models was about art and artistic and technical skill and was also an emotional process, especially because cooperation with others in building the models was fun. Based on learning research $[15,30,60]$, hands-on learning and involvement of positive emotions lead to deeper learning and a better retention of the matter learned. Earlier findings of the learning outcomes of the Math and Art Project support this [32].

One of the most interesting and encouraging results of this study was that the lowest achievers liked learning math in the exhibition context, and they preferred it over the school context. This is in line with some recent results relating to a dinosaur exhibition and the use of AR (Augmented Reality) in informal learning [61]. However, these results contradict the earlier reports in the literature [cf. [62]], which indicates that the high achievers benefit from the informal learning settings like science center exhibitions most of all.

The fact that the present study shows that the high achievers preferred the school context is curiosity provoking and gives cause for further consideration. In the next part, we explore possible reasons for the results by using Brady and Kumar's [63] "motive of inventor" and Sternberg's [64] view of creativity as the reflection surface. It is interesting to consider what the role might be of emotions such as math anxiety, fear of a challenge, or the excitement of breaking an old habit in a novel learning situation that the pupils face in the informal math exhibition.

5.1. "Motive of Inventor" by Brady and Kumar [63]. Because math problems were approached from a new perspective, one could not anymore self-evidently operate or think as before. Instead, the math and art experience might have led to a reconceptualization of math being a formal, solidified, difficult school subject, which is hard to approach and learn. The same approach, even just a fun hands-on experiment, did not necessarily fit everybody, as could be hypothesized based on the literature $[9,14]$.

Some pupils reported that they gained from the artistic hands-on approach in the exhibition, and they might be characterized as creative individuals that Sternberg [64] describes "are willing to go their own way." Further, Sternberg [64] states they are those who "(a) redefine problems in novel ways, (b) take sensible risks, (c) 'sell' ideas that others might not initially accept, (d) persevere in the face of obstacles, and (e) examine whether their own preconceptions are interfering with their creative process."

On the other hand "the motive of inventor" [63] can have attracted those pupils suffering from math anxiety. The artistic hands-on approach might have been seen as a welcomed relief; that is, instead of "leaning on mathematics of others," a self-initiated inquiry was encouraged [26]. It might have supported pupils to overcome difficulties, which the traditional math teaching at school sometimes can cause, 
and it may have been useful to many of those pupils who consider mathematics to be not meant for them.

The same artistic hands-on process might, however, have alienated those who were less flexible. They probably considered that math had lost its worth due to the fun and play aspect experienced at the exhibition and when the subject was within easier reach of everyone.

5.2. Bridging Is Needed for Transfer. One of the most important findings is that there seems to be a hidden risk in the process: the experience of the hands-on effectiveness and worth of mathematics were shown to be distinct entities, and in pupils' minds the school and the exhibition are likely to form quite different worlds. Thus, it is important that the $4 \mathrm{D}$ Math and Art Project, as well as other similar projects in the future, does not remain simply as one more fun experience. Instead, it is important that the learned observation and thinking skills transfer into the further mathematical studies of pupils. To ensure this, teachers need to wisely support their pupils to build a bridge and make a connection between learning at the exhibition and learning in the classroom. Further, this will help to find the meaning of the math and art approaches and in the end the meaning of mathematics itself.

All in all, the hands-on and art approach to math involving touching and seeing helped pupils to produce creative results, which otherwise would not have come into the world. In the building project, pupils had to continuously change from the observation of details to observing the whole and back, which prevented pupils from becoming stuck and which supported the testing of ideas and flexible thinking - a prerequisite of development of cognition and creativity. According to Hope [20], the visual representation shows the cognitive learning outcome, the thinking results of the pupils, and how they have found the key spatial characteristics of the problem in concern. One can assume that this kind of process also promotes consciousness and metacognition in students, which are important goals of math education [16]. As such, the next step concerning the project will be most interesting, as we will use video analysis and focus on examination of the building process and the resulting visual models.

In fact, the process of building the hands-on art and math structures resembled a lot the process of computer programming, where everything is based on totally reduced units of 1 and 0 . In the 4D Math system, the pupils had only four types of units to create different structures and creatures. Now, bridging the gap between the general mathematical competence and the increasingly computational contemporary culture, the power of curiosity, imagination, and play by Görlitz [4] is forming the link between the real material world and the totally digitalized environments.

\section{Conflicts of Interest}

The authors declare that they have no conflicts of interest.

\section{References}

[1] R. Driver, R. J. Leach, P. Millar, and P. Scott, Young Peoples Images of Science, Open University Press, Buckingham, England, 1996.

[2] M. Braund and M. Reiss, Learning Science Outside the Classroom, Taylor \& Francis, Abingdon, UK, 2004.

[3] M. Fenichel and H. Scheingruber, Surrounded by Science, The National Academies Press, Washington, USA, 2010.

[4] D. Görlitz, "Exploration and attribution in developmental context," in Curiosity, Imagination and Play: on The Development of Spontaneous Cognitive and Motivational Processes, Görlitz. and J. Wohlwill, Eds., Lawrence Erlbaum, New Jersey, NJ, USA, 1987.

[5] I. Mullis, M. Martin, and T. Loveless, International trends in mathematics and science achievement, curriculum, and instruction, 271 p., TIMSS and PIRLS International Study Center, Lynch School of Education, Boston College, U.S., 2016.

[6] G. Yakman and H. Lee, "Exploring the examplary STEAM education in the U.S. practical educational framework for Korea," Journal of The Korean Association For Science Education, vol. 32, no. 6, pp. 1072-1086, 2012.

[7] J. Piaget, J. Grize, A. Szeminska, and V. Bang, Epistemology and Psychology of Functions, Springer Netherlands, Dordrecht, Netherlands, 1977.

[8] J. Dewey, "Experience and Education," in The Kappa Delta Pi Lecture Series. Collier Books, Collier Books, New York, NY, USA, 1938.

[9] F. Oppenheimer, "A rationale for a science museum," Curator: The Museum Journal, vol. 11, no. 3, pp. 206-209, 1968.

[10] B. Ojose, "Applying piagets theory of cognitive development to mathematics instruction," The Mathematics Educator, vol. 18, no. 1, pp. 26-30, 2008.

[11] A. Craft, Creativity in Schools: Tensions and Dilemmas, Routledge, Abingdon, UK, 2005.

[12] E. L. Mann, "The search for mathematical creativity: Identifying creative potential in middle school students," Creativity Research Journal, vol. 21, no. 4, pp. 338-348, 2009.

[13] B. Sriraman, "Are giftedness and creativity synonyms in mathematics?" Journal of Secondary Gifted Education, vol. 17, no. 1, pp. 20-36, 2016.

[14] E. Mofield, M. Parker-Peters, and S. Chakraborti-Ghosh, "Perfectionism, coping, and underachievement in gifted adolescents: avoidance vs. approach orientations," Educational Science, vol. 6, no. 3, pp. 21-33, 2016.

[15] T. E. Scruggs and M. A. Mastropieri, "Current approaches to science education: implications for mainstream instruction of students with disabilities," Remedial and Special Education, vol. 14, no. 1, pp. 15-24, 1993.

[16] Y. Lai, X. Zhu, Y. Chen, and Y. Li, "Effects of mathematics anxiety and mathematical metacogntiion on word problem solving in children with and without mathematical learning difficulties," PLOS ONE, 2015.

[17] R. Ballantyne and J. Packer, "Introducing a fifth pedagogy: experience-based strategies for facilitating learning in natural environments," Environmental Education Research, vol. 15, no. 2, pp. 243-262, 2009.

[18] F. J. Brigham, T. E. Scruggs, and M. A. Mastropieri, "Science Education and Students with Learning Disabilities," Learning Disabilities Research \& Practice, vol. 26, no. 4, pp. 223-232, 2011. 
[19] C. B. McCarthy, "Effects of thematic-based, hands-on science teaching versus a textbook approach for students with disabilities," Journal of Research in Science Teaching, vol. 42, no. 3, pp. 245-263, 2005.

[20] G. Hope, "Thinking and learning through drawing: in primary classrooms," Thinking and Learning Through Drawing: In Primary Classrooms, pp. 1-182, 2008.

[21] D. E. Gullatt, "Enhancing student learning through arts integration: implications for the profession," The High School Journal, vol. 91, no. 4, pp. 12-25, 2008.

[22] J. Wai, D. Lubinski, and C. P. Benbow, "Spatial ability for STEM domains: aligning over 50 years of cumulative psychological knowledge solidifies its importance," Journal of Educational Psychology, vol. 101, no. 4, pp. 817-835, 2009.

[23] K. Fenyvesi, R. Koskimaa, and Z. Lavicza, "Experiential Education of Mathematics: Art and Games for Digital Natives," Kasvatus Ja Aika, vol. 9, no. 1, pp. 107-134, 2015.

[24] X. Ge, D. Ifenthaler, and J. M. Spector, Emerging Technologies for STEAM Education, Springer International Publishing, Cham, 2015.

[25] D. Wilmot and J. Schäfer, "Visual arts and the teaching of the mathematical concepts of shape and space in Grade R classrooms," South African Journal of Childhood Education, vol. 5, no. 1, p. 23, 2015.

[26] A. Mack, "A Deweyan Perspective On Aesthetic In Mathematics Education," Philosophy of Mathematics Education Journal, vol. 19, 2006.

[27] J. Dewey, “Art as Experience," p. 371, The Berkley Publishing Group, Penguin, 1980.

[28] E. Eisner, The Arts and Creation of Mind, Donnelley and Sons, Harrisonburg, Va, USA, 2002.

[29] R. Hickman and P. Huckstep, "Art and mathematics in education," Journal of Aesthetic Education, vol. 37, no. 1, pp. 1-12, 2003.

[30] R. Sylwester, "How emotions affect learning. Reporting what students are learning," Educational Leadership, vol. 52, no. 2, pp. 69-82, 1994.

[31] SINUS, Towards new teaching in mathematics, Eds. C. Baptist and D. Raab, University of Bayreuth, Germany, 2012.

[32] N. W. Sochacka, K. W. Guyotte, and J. Walther, "Learning together: a collaborative autoethnographic exploration of STEAM (STEM + the Arts) education," Journal of Engineering Education, vol. 105, no. 1, pp. 15-42, 2016.

[33] M.-P. Vainikainen, H. Salmi, and H. Thuneberg, "Situational Interest an Learning in a science center mathematics exhibition," Journal of Research in STEM Education, vol. 1, no. 1, pp. 15-29, 2015.

[34] I. Illich, Deschooling Society, Harper and Row, New York, NY, USA, 1971.

[35] H. Gardner, The Unschooled Mind: How Children Think and How Schools Should Teach, USA, BasicBooks, 1991.

[36] A. Mattila, Seeing things in a new light: reframing in therapeutic conversations, Research reports 67, Rehabilitation Foundation, Helsinki, 2001.

[37] H. Salmi, M.-P. Vainikainen, and H. Thuneberg, "Mathematical thinking skills, self-concept and learning outcomes of 12-yearolds visiting a mathematics science centre exhibition in Latvia and Sweden," Journal of Science Communication, vol. 14, no. 4, pp. 1-19, 2015.

[38] A. Manninen, 4DFrame - a new pedagogical material, A practical study, Sodertorn University, 2010.
[39] R. M. Ryan and J. P. Connell, "Perceived locus of causality and internalization: examining reasons for acting in two domains," Journal of Personality and Social Psychology, vol. 57, no. 5, pp. 749-761, 1989.

[40] J. Raven, J. C. Raven, and J. Court, Manual for Raven's progressive matrices and vocabulary scales, OPP Limited, Oxford, UK. 2003.

[41] R. Bakeman, "Recommended effect size statistics for repeated measures designs," Behavior Research Methods, vol. 37, no. 3, pp. 379-384, 2005.

[42] R. Cummins, The Comprehensive quality of life scale manual (2nd ed.). Melbourne: Deakin University, Psycholgy Research Center, 1995.

[43] M. Zimmerman, C. J. Ruggero, I. Chelminski et al., "Developing brief scales for use in clinical practice: the reliability and validity of single-item self-report measures of depression symptom severity, psychosocial impairment due to depression, and quality of life," The Journal of Clinical Psychiatry, vol. 67, no. 10, pp. 1536-1541, 2006.

[44] L. Bergkvist and J. R. Rossiter, "The predictive validity of multiple-item versus single-item measures of the same constructs," Journal of Marketing Research, vol. 44, no. 2, pp. 175184, 2007.

[45] C. Fuchs and A. Diamantapolous, "Using single-item measures for contruct measurement research: conceptual issues and applicationguidelines," Die Betriebswirtschaft, vol. 69, no. 2, pp. 197-212, 2009.

[46] C. Waltz, O. Strickland, and E. Len, Measurement in nursing research. Philadelphia: FA Davis, 1991.

[47] J. P. Wanous, A. E. Reichers, and M. J. Hudy, "Overall job satisfaction: how good are single-item measures?" Journal of Applied Psychology, vol. 82, no. 2, pp. 247-251, 1997.

[48] A. M. Abdel-Khalek, "Measuring happiness with a single-item scale," Social Behavior and Personality, vol. 34, no. 2, pp. 139-150, 2006.

[49] J. R. Rossiter, "The C-OAR-SE procedure for scale development in marketing," International Journal of Research in Marketing, vol. 19, no. 4, pp. 305-335, 2002.

[50] W.-Y. Poon, K. Leung, and S.-Y. Lee, "The comparison of single item constructs by relative mean and relative variance," Organizational Research Methods, vol. 5, no. 3, pp. 275-298, 2002.

[51] L. Becker, Analysis of pretest and posttest scores with gain scores and repeated measures, http://www.uccs.edu/lbecker/ gainscore.html, 2000.

[52] B. M. Byrne, "Structural equation modeling with AMOS: Basic concepts, applications, and programming, second edition," Structural Equation Modeling with AMOS: Basic Concepts, Applications, and Programming, Second Edition, pp. 1-396, 2013.

[53] M. Burns and R. Silbey, So You Have to Teach Math: Sound Advice for K-6 Teachers, Abe Books, Sacramento, Calif, USA, 2008.

[54] W. S. Grolnick and R. M. Ryan, "Self-perceptions, motivation, and adjustment in children with learning disabilities: a multiple group comparison study," Journal of Learning Disabilities, vol. 23, no. 3, pp. 177-184, 1990.

[55] P. Jalil, M. Abu Sbeih, M. Boujetiff, and R. Barakat, "Autonomy in science education: A practical approach in attitude shifting towards science learning," Journal of Science Education and Technology, vol. 18, no. 2, pp. 476-486, 2009. 
[56] J. Osborne, S. Simon, and S. Collins, "Attitudes towards science: a review of the literature and its implications," International Journal of Science Education, vol. 25, no. 9, pp. 1049-1079, 2003.

[57] C.-Y. Lin and S. Cho, "Predicting creative problem-solving in math from a dynamic system model of creative problem solving ability," Creativity Research Journal, vol. 23, no. 3, pp. 255-261, 2011.

[58] J. Falk and L. Dierking, Lessons without Limit. Walnut Creek, CA: AltaMira, 2002.

[59] L. Rennie, "Learning science outside of school," in In Handbook of Research on Science Education, N. Lederman and S. Abell, Eds., vol. 2, Routledge, London and New York, 2014.

[60] A. Elster and P. Ward, "Learning math through the arts," in Mathematics and Culture, M. Emmer, Ed., Springer, New York, NY, USA, 2007.

[61] H. Salmi, H. Thuneberg, and M. Vainikainen, "Learning with the dinosaurs: a study on motivation, cognitive reasoning, and making observations," International Jopurnal of Science Education, Part B, vol. 7, no. 3, pp. 203-217, 2017.

[62] H. Salmi, H. Thuneberg, and M. Vainikainen, "Making the invisible observable by Augmented Reality in informal science education context," International Journal of Science Education, Part B, vol. 7, no. 3, pp. 253-268, 2017.

[63] I. Brady and A. Kumar, "Some thoughts on sharing science," Science Education, vol. 84, no. 4, pp. 507-523, 2000.

[64] R. J. Sternberg, "The assessment of creativity: an investmentbased approach," Creativity Research Journal, vol. 24, no. 1, pp. 3-12, 2012. 


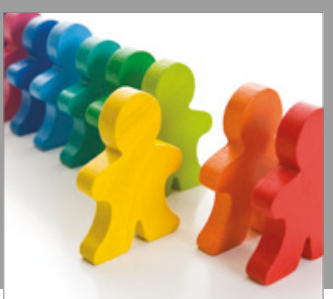

Autism

Research and Treatment
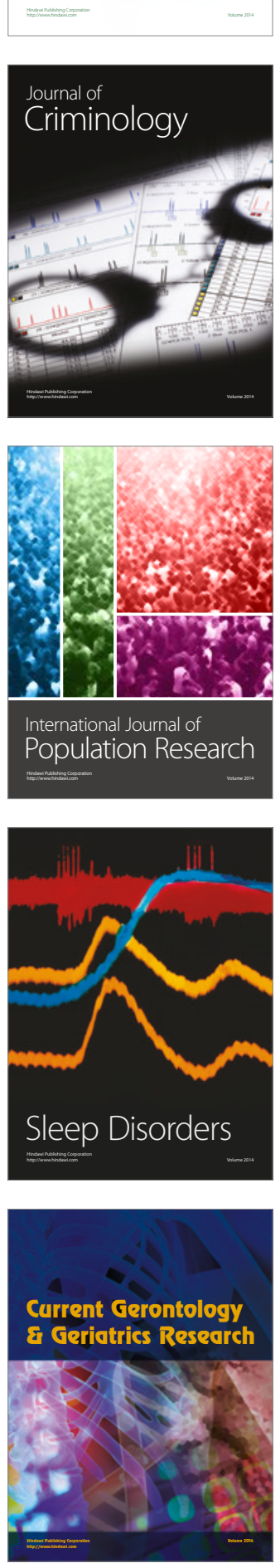

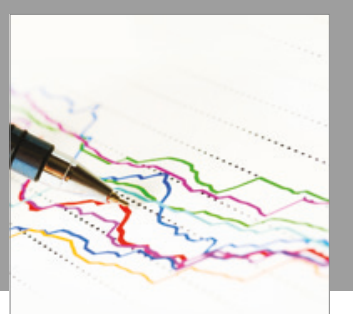

Economics

Research International

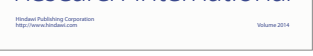

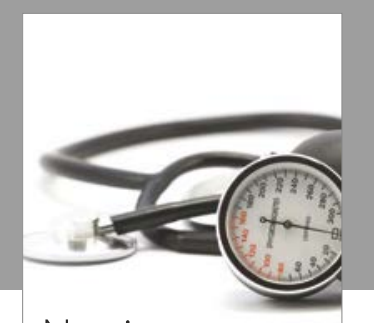

Nursing

Research and Practice

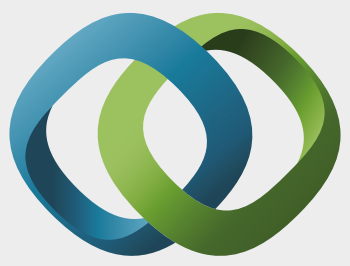

\section{Hindawi}

Submit your manuscripts at

https://www.hindawi.com
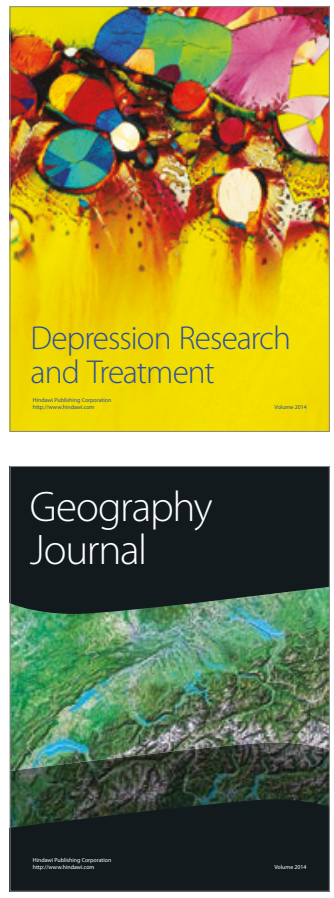
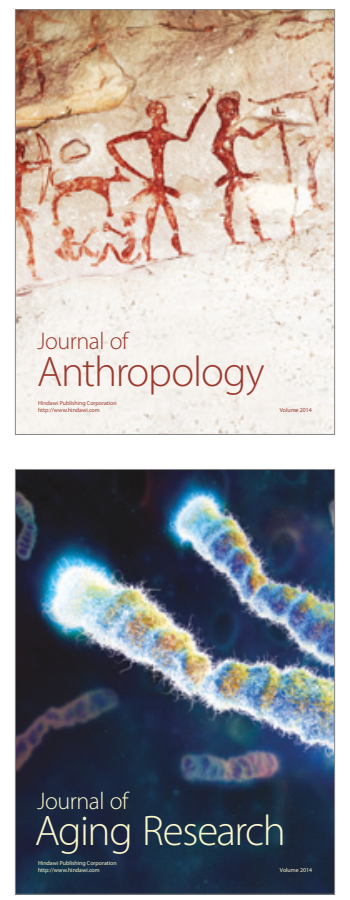
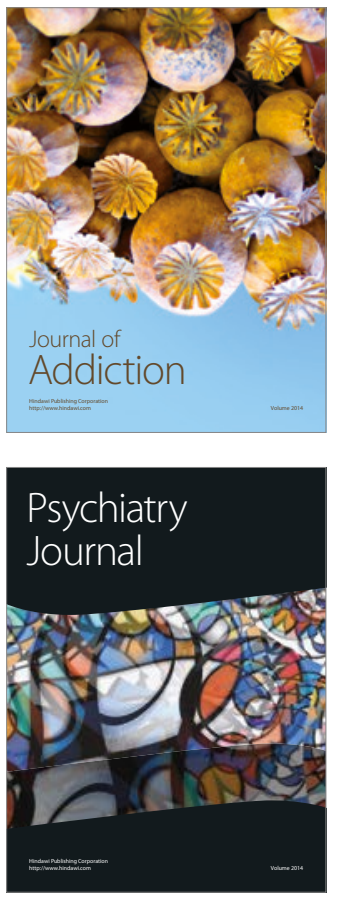

Child Development

Research

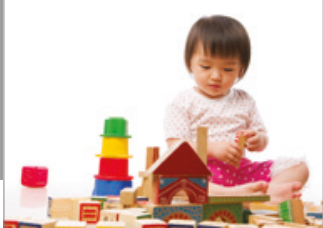

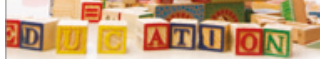
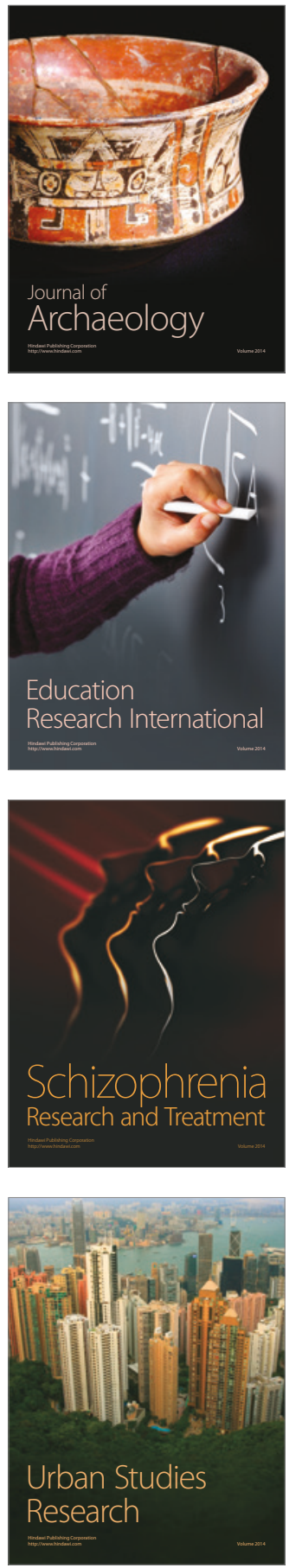